\title{
Evaluation of Oxidative Stress as a Contributor of Anesthetic Agents' Effects on Embryo Quality and ICSI Outcome in Iraqi Patients
}

\author{
Athraa Abd Alhussain 1, Raad Ghazi Reshan ${ }^{1}$, Hayder A. L. Mossa 1 \\ ${ }^{1}$ High Institute of Infertility Diagnosis and Assisted Reproductive Technologies, Al Nahrain University, Baghdad, Iraq. \\ biologestathraa@gmail.com
}

Infertility is described as a couple's failure to conceive for at least a year, using unprotected sex. Even though all anesthetic chemicals have been revealed in the follicular fluids, general anesthesia is still used in many IVF centers for patients who want to get pregnant. This study included 60 infertile women randomly divided into two groups under general anesthesia. 30 patients were given a Ketamine dose of $0.5 \mathrm{mg} / \mathrm{Kg}$ and the other 30 patients were received Remifentanil dose of $0.5 \mu \mathrm{g} / \mathrm{Kg}$ for induction of anesthesia. We collected serum for Reactive Oxygen Species (ROS) levels assessment for all patients before and after starting general anesthesia. Routine ICSI procedures was performed on all participants, including clinical evaluation (history, examination, and investigation), controlled ovarian and ovulation stimulation, oocyte retrieval under general anesthesia, follicular fluid collection for postoperative anesthesia medication concentration (Remifentanil and Ketamine), oocyte stripping, oocyte maturity assessment, intra-oocyte sperm injection into mature cells (MII), fertilization and division evaluation and embryo categorization, embryo selection and transfer, luteal phase support, and beta-hCG determination. ROS concentrations were compared between the Remifentanil and Ketamine groups. There was no significant difference in embryo features between Remifentanil and Ketamine, indicating that neither one is superior to the other in this regard. When Remifentanil or Ketamine was taken, there was no significant difference in ROS levels in serum or follicular fluid.

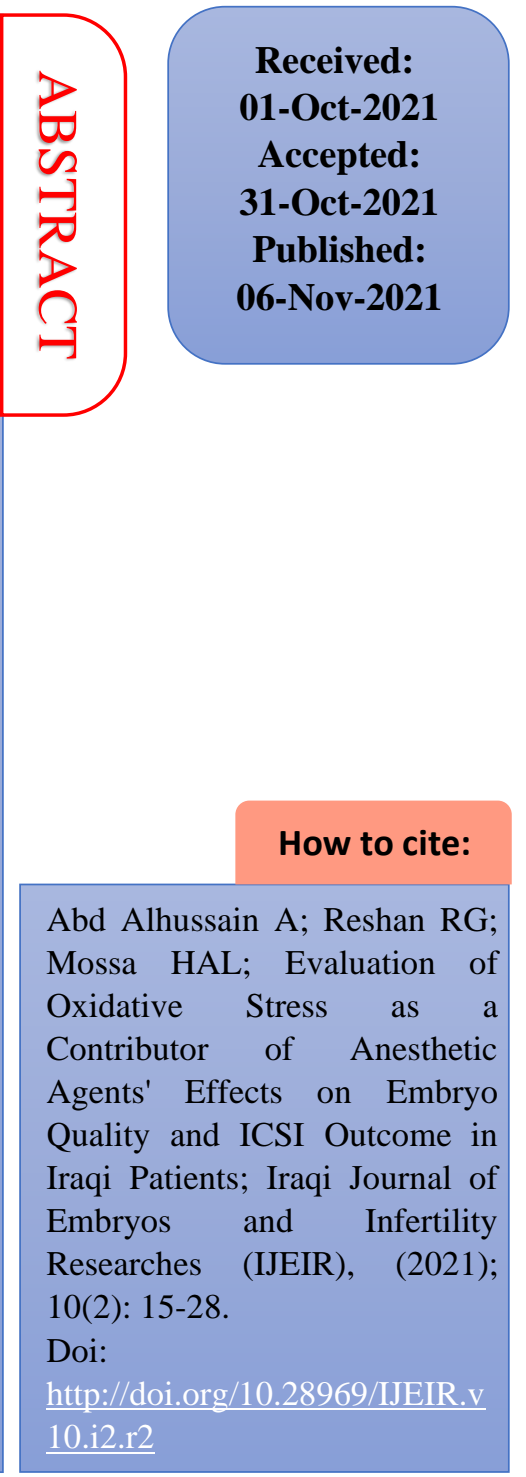

KEYWORDS

Ketamine, Remifentanil, Reactive Oxygen Species, Oocyte Quality, General Anaesthesia 


\section{Introduction}

The quality of gametes and their interactions is affected by oxidative stress (OS). Free radicals, such as Reactive Oxygen Species (ROS), influence oocytes, spermatozoa, and embryos, as well as their environment. The microenvironments associated with follicular fluid, hydrosalpingeal fluid, and peritoneal fluid affect oocyte quality, sperm-oocyte interaction, sperm-mediated oocyte activation, implantation, and early embryo development. OS affects early embryo development and implantation, which has an impact on conception rates (Griveau and Lannou ${ }^{[1]}$ ). ROS are assumed to play a key function within the ovary because aerobic metabolism - which produces ROS by consuming oxygen - is required for the energy requirements of oocytes and embryos (Agarwal, et al. ${ }^{[2]}$ ). Oxidative stress has been connected to the management of cyclical variations in the endometrium. In the late secretory phase, ROS levels rise soon before menstruation, implying that they play a role in the process (Jauniaux, et al. ${ }^{[3]}$ ). By causing damage to the embryo cell membrane as well as apoptosis, oxidative stress is thought to play a role in aberrant embryo development (Joham, et al. ${ }^{[4]}$ ). Anesthetic treatment for oocyte retrieval may impair the results and success rates of in vitro fertilization (IVF). The effects of two different anaesthetic techniques for oocyte retrieval were examined in this study (general anaesthesia vs. sedation) as a result of IVF For general anaesthesia, we used a hypnotic dosage of Remifentanil (UltivaTM) with either propofol or isoflurane. Midazolam, diazepam, or propofol were used to achieve sedation, depending on clinical needs (Urfalioglu, $\mathbf{A}^{[5]}$ ). Remifentanil was first developed in the early 1990s and is a clinically flexible opioid. It is administered intravenously to induce drowsiness and analgesia in patients enduring painful surgical procedures, with little effect on cognition (Mohsin, et al ${ }^{[6]}$ ). Ketamine was developed in the 1960s as a possible replacement for phencyclidine, a potent hallucinogenic drug. It's a synthetic dissociative anesthetic that's nonbarbiturate (Liu, et al. ${ }^{[7]}$ ). 


\section{Materials and Methods}

The study included 60 infertile women randomly divided into two groups. All patients took general anesthesia, 30 patients were given a Ketamine dose of $0.5 \mathrm{mg} / \mathrm{Kg}$ and the other 30 patients were administered with a Remifentanil dose of $0.5 \mu \mathrm{g} / \mathrm{Kg}$ for induction of anesthesia. Infertile females who were receiving intracytoplasmic sperm injection (ICSI) were used in this study at the infertility center of High Institute of Infertility Diagnosis and Assisted Reproductive Technologies, Al Nahrain University, Baghdad, Iraq, during the period from July 2020 until December 2021 regardless to the presence or absence of previous Assisted Reproductive Technologies (ARTs) trials. In the ICSI laboratory of the High Institute of Infertility Diagnosis and Assisted Reproductive Technologies, the morphological assessment of oocytes aspirated from the ovaries of infertile females and their resultant embryos was performed. The detection of ROS in follicular fluid and serum was done using an enzyme-linked immunosorbent assay (ELISA) kit at a private laboratory.

\section{Results}

The participants in this study were 60 infertile women who were divided into two groups: 30 women who got Remifentanil during general anesthesia for oocyte retrieval and 30 women who received Ketamine during general anesthesia for oocyte retrieval. The sociodemographic characteristics and smoking habit of the participants in this study are shown in Table 1. The mean age of Remifentanil group was $31.83 \pm 5.34$ years and that of Ketamine group was $32.80 \pm 3.95$ years and there was no significant difference in mean age between both groups $(p=0.429)$. Most of women in both groups were older than 35 years of age, $20(66.7 \%)$ and $22(73.3 \%)$, respectively. There was also no significant difference in mean body mass index (BMI) between both groups $(\mathrm{p}=0.051), 27.78 \pm 4.01$ $\mathrm{Kg} / \mathrm{m}^{2}$ and $25.97 \pm 2.95 \mathrm{Kg} / \mathrm{m}^{2}$, respectively. Overall, most of the women in both groups were either overweight or obese since women with normal weight accounted for less than $50 \%$ in either group. The mean duration of infertility of women in the Remifentanil group was $8.63 \pm 4.60$ years, while that of women in 
the Ketamine group was $6.27 \pm 4.54$ years, but the difference in mean duration of infertility between both groups was not significant $(\mathrm{p}=$ 0.052). Only two women were admitted to be active smokers, one in the Remifentanil group and the other one in the Ketamine group. There was no significant difference in the proportion of relative couples in both groups $(\mathrm{p}=0.190)$. There was also no significant difference in the frequency distribution of women according to type of infertility, primary versus secondary, between Remifentanil and Ketamine groups ( $p$ $=0.067)$. However, the majority of women in either group were suffering from primary infertility, $20(66.7 \%)$ versus $26(86.7 \%)$, respectively. In addition, there was significant difference in the frequency distribution of women according to cause of infertility between Remifentanil and Ketamine groups ( $p$ $=0.436)$. The most frequent cause of infertility in both groups was combined factor, followed by female factor then by male factor and lastly by unexplained cause. Male and female causes of infertility are shown in Table 1 . History of previous in vitro fertilization attempts have been reported in 7 (23.3\%) of Remifentanil group and $1(3.3 \%)$ of Ketamine group and the outcome was successful in a single woman in both groups. The comparison of ROS concentrations between groups is shown in Table 2 and Table 3. There was no significant difference in median serum ROS concentrations before anesthesia between both groups $(p=0.051)$. There was also, no significant difference in median serum ROS concentrations after anesthesia between Remifentanil and Ketamine groups $(\mathrm{p}=$ 0.367). In addition, there was no significant difference in median follicular fluid ROS concentrations between both groups ( $\mathrm{p}=$ 0.051). There was also no significant difference in median fertilized two pronuclei $(2 \mathrm{PN})$ oocyte count between the groups $(\mathrm{p}=$ 0.175). Furthermore, there was no significant difference in median total transferred embryo count between both groups $(\mathrm{p}=0.415)$ as shown in Table 4. Added to that, there was no significant difference in median grade 1 (G1) embryo count between Remifentanil and Ketamine groups $(\mathrm{p}=0.753)$. 
Table (1): Sociodemographic characteristics and smoking habit of infertile women enrolled in this study

\begin{tabular}{|c|c|c|c|c|}
\hline \multicolumn{2}{|c|}{ Characteristic } & $\begin{array}{c}\text { Remifentanil } \\
n=\mathbf{3 0}\end{array}$ & $\begin{array}{c}\text { Ketamine } \\
n=30\end{array}$ & $p$ \\
\hline \multirow{4}{*}{ Age (Years) } & Mean \pm SD & $31.83 \pm 5.34$ & $32.80 \pm 3.95$ & \multirow{4}{*}{$\begin{array}{l}0.429 \mathrm{I} \\
\mathrm{NS}\end{array}$} \\
\hline & Range & $20(39.0 \%)$ & $22(39.0 \%)$ & \\
\hline & $<35, n(\%)$ & $10(33.3 \%)$ & $8(26.7 \%)$ & \\
\hline & $\geq 35, n(\%)$ & $20(66.7 \%)$ & $22(73.3 \%)$ & \\
\hline \multirow{6}{*}{ BMI $\left(\mathrm{kg} / \mathrm{m}^{2}\right)$} & Mean \pm SD & $27.78 \pm 4.01$ & $25.97 \pm 2.95$ & \multirow{6}{*}{$\begin{array}{l}0.051 \mathrm{I} \\
\mathrm{NS}\end{array}$} \\
\hline & Range & $21.83-38.29$ & $21.76-32.05$ & \\
\hline & Normal, $n(\%)$ & $8(26.7 \%)$ & $12(40.0 \%)$ & \\
\hline & Overweight, $n(\%)$ & $13(43.3 \%)$ & $15(50.0 \%)$ & \\
\hline & Class I obesity, $n(\%)$ & $8(26.7 \%)$ & $3(10.0 \%)$ & \\
\hline & Class II obesity, $n(\%)$ & $1(3.3 \%)$ & $0(0.0 \%)$ & \\
\hline \multirow{2}{*}{$\begin{array}{c}\text { Infertility Duration } \\
\text { (years) }\end{array}$} & Mean \pm SD & $8.63 \pm 4.60$ & $6.27 \pm 4.54$ & \multirow{2}{*}{$\begin{array}{l}0.052 \mathrm{I} \\
\mathrm{NS}\end{array}$} \\
\hline & Range & $2-17$ & $1(18.0 \%)$ & \\
\hline \multirow{3}{*}{ Smoking } & Active smoker, $n(\%)$ & $1(3.3 \%)$ & $1(3.3 \%)$ & \multirow{3}{*}{$\begin{array}{c}0.151 \mathrm{C} \\
\mathrm{NS}\end{array}$} \\
\hline & Passive smoker, $n(\%)$ & $9(30.0 \%)$ & $3(10.0 \%)$ & \\
\hline & Nonsmoker, $n(\%)$ & $20(66.7 \%)$ & $26(86.7 \%)$ & \\
\hline \multirow{2}{*}{ Couples are relatives } & Yes, $n(\%)$ & $15(50.0 \%)$ & $10(33.3 \%)$ & \multirow{2}{*}{$\begin{array}{c}0.190 \mathrm{C} \\
\mathrm{NS}\end{array}$} \\
\hline & No, $n(\%)$ & $15(50.0 \%)$ & $20(66.7 \%)$ & \\
\hline \multirow{2}{*}{ Type of infertility } & Primary, $n(\%)$ & $20(66.7 \%)$ & $26(86.7 \%)$ & \multirow{2}{*}{$\begin{array}{c}0.067 \mathrm{C} \\
\mathrm{NS}\end{array}$} \\
\hline & Secondary, $n(\%)$ & $10(33.3 \%)$ & $4(13.3 \%)$ & \\
\hline \multirow{4}{*}{ Cause of infertility } & Female factor, $n(\%)$ & $5(16.7 \%)$ & $5(16.7 \%)$ & \multirow{4}{*}{$\begin{array}{c}0.436 \mathrm{C} \\
\mathrm{NS}\end{array}$} \\
\hline & Male factor, $n(\%)$ & $11(36.7 \%)$ & $7(23.3 \%)$ & \\
\hline & Combined, $n(\%)$ & $13(43.3 \%)$ & $14(46.7 \%)$ & \\
\hline & Unexplained, $n(\%)$ & $1(3.3 \%)$ & $4(13.3 \%)$ & \\
\hline \multirow{5}{*}{ Male factor } & Oligozoospermia, $n(\%)$ & $7(23.3 \%)$ & $6(20.0 \%)$ & \multirow{5}{*}{$\begin{array}{c}0.519 \mathrm{C} \\
\mathrm{NS}\end{array}$} \\
\hline & Asthenozoospermia, $n(\%)$ & $11(36.7 \%)$ & $7(23.3 \%)$ & \\
\hline & SOAT, $n(\%)$ & $3(10.0 \%)$ & $8(26.7 \%)$ & \\
\hline & Morph, $n(\%)$ & $1(3.3 \%)$ & $1(3.3 \%)$ & \\
\hline & Normal, $n(\%)$ & $8(26.7 \%)$ & $8(26.7 \%)$ & \\
\hline \multirow{3}{*}{ Female factor } & Poor reserve, $n(\%)$ & $3(10.0 \%)$ & $7(23.3 \%)$ & \multirow{3}{*}{$\begin{array}{c}0.256 \mathrm{C} \\
\mathrm{NS}\end{array}$} \\
\hline & Normal, $n(\%)$ & $13(43.3 \%)$ & $14(46.7 \%)$ & \\
\hline & Hyper, $n(\%)$ & $14(46.7 \%)$ & $9(30.0 \%)$ & \\
\hline \multirow{2}{*}{ History of IVF } & Yes, $n(\%)$ & $7(23.3 \%)$ & $1(3.3 \%)$ & \multirow{2}{*}{$\begin{array}{c}0.058 \mathrm{Y} \\
\mathrm{NS}\end{array}$} \\
\hline & No, $n(\%)$ & $23(76.7 \%)$ & $29(96.7 \%)$ & \\
\hline \multirow{2}{*}{ Outcome } & Success, $n(\%)$ & $1(3.3 \%)$ & $1(3.3 \%)$ & \multirow{2}{*}{$\begin{array}{l}0.250 \mathrm{~F} \\
\mathrm{NS}\end{array}$} \\
\hline & Failure, $n(\%)$ & $6(20.0 \%)$ & $0(0.0 \%)$ & \\
\hline
\end{tabular}

$\boldsymbol{n}$ : number of cases; SD: standard deviation; BMI: body mass index; IVF: in vitro fertilization; I: independent samples $t$-test; C: Chi-square test; Y: Yates correction test; F: Fischer exact test; NS: not significant at $p>0.05$ 
Table (2): Comparison of reactive oxygen species (ROS) concentrations between Remifentanil and Ketamine groups

\begin{tabular}{|c|c|c|c|}
\hline Characteristic & $\begin{array}{c}\text { Remifentanil } \\
\qquad n=\mathbf{3 0}\end{array}$ & $\begin{array}{c}\text { Ketamine } \\
\qquad \begin{array}{c}n=\mathbf{3 0}\end{array}\end{array}$ & $p$ \\
\hline \multicolumn{4}{|c|}{ ROS Before anesthesia U/I } \\
\hline Median (IQR) & $1550.10(2280.49)$ & $661.17(697.84)$ & \multirow{2}{*}{$\begin{array}{c}0.051 \mathrm{M} \\
\mathrm{NS}\end{array}$} \\
\hline Range & $148.05-5160.42$ & $153.12-975000.00$ & \\
\hline \multicolumn{4}{|c|}{ ROS After anesthesia U/I } \\
\hline Median (IQR) & $1064.50(1770.08)$ & $783.54(545.34)$ & \multirow{2}{*}{$\begin{array}{c}0.367 \mathrm{M} \\
\mathrm{NS}\end{array}$} \\
\hline Range & $163.31-4092.15$ & $176.76-2531.78$ & \\
\hline
\end{tabular}

$\boldsymbol{n}$ : number of cases; IQR: inter-quartile range; M: Mann Whitney U test; NS: not significant at $p$ > 0.05

Table (3): Comparison of ROS concentrations in follicular fluid between Remifentanil and Ketamine groups

\begin{tabular}{|c|c|c|c|}
\hline \multicolumn{4}{|c|}{ ROS In follicular fluid U/I } \\
\cline { 1 - 2 } Median (IQR) & $860.79(2095.46)$ & $864.64(739.78)$ & $0.848 \mathrm{M}$ \\
Range & $130.89-4571.99$ & $239.20-2757.86$ & NS \\
\hline
\end{tabular}

$\boldsymbol{n}$ : number of cases; IQR: inter-quartile range; M: Mann Whitney U test; NS: not significant at $p$ > 0.05 
Table (4): Comparison of fertility parameters between Remifentanil and Ketamine groups

\begin{tabular}{|c|c|c|c|}
\hline Characteristic & $\begin{array}{c}\text { Remifentanil } \\
n=\mathbf{3 0}\end{array}$ & $\begin{array}{c}\text { Ketamine } \\
n=\mathbf{3 0}\end{array}$ & $p$ \\
\hline \multicolumn{4}{|c|}{ Fertilized, 2 pronuclei (2PN) oocytes } \\
\hline Median (IQR) & $4.50(4.00)$ & $4.00(2.00)$ & \multirow{2}{*}{$\begin{array}{c}0.175 \mathrm{M} \\
\mathrm{NS}\end{array}$} \\
\hline Range & $2.00-13.00$ & $0.00-11.00$ & \\
\hline \multicolumn{4}{|c|}{ Number of transferred embryos } \\
\hline Median (IQR) & $3.00(2.00)$ & $3.00(2.00)$ & \multirow{2}{*}{$\begin{array}{c}0.415 \mathrm{M} \\
\mathrm{NS}\end{array}$} \\
\hline Range & $1.00-4.00$ & $1.00-4.00$ & \\
\hline \multicolumn{4}{|c|}{ Grade 1 (G1) embryos } \\
\hline Median (IQR) & $2.00(2.00)$ & $2.00(1.00)$ & \multirow{2}{*}{$\begin{array}{c}0.753 \mathrm{M} \\
\mathrm{NS}\end{array}$} \\
\hline Range & $0.00-4.00$ & $0.00-4.00$ & \\
\hline \multicolumn{4}{|c|}{ Grade 2 (G2) embryos } \\
\hline Median (IQR) & $0.50(1.00)$ & $1.00(2.00)$ & \multirow{2}{*}{$\begin{array}{c}0.230 \mathrm{M} \\
\mathrm{NS}\end{array}$} \\
\hline Range & $0.00-3.00$ & $0.00-3.00$ & \\
\hline \multicolumn{4}{|c|}{ Grade 3 (G3) embryos } \\
\hline Median (IQR) & $0.00(0.00)$ & $0.00(0.00)$ & \multirow{2}{*}{$\begin{array}{c}0.430 \mathrm{M} \\
\mathrm{NS}\end{array}$} \\
\hline Range & $0.00-3.00$ & $0.00-3.00$ & \\
\hline
\end{tabular}

$\boldsymbol{n}$ : number of cases; IQR: inter-quartile range; M: Mann Whitney U test; NS: not significant at $p>$ 0.05

Table (5): Comparison of rate of biochemical pregnancy outcome between Remifentanil and Ketamine groups

\begin{tabular}{|c|c|c|c|}
\hline Biochemical pregnancy & $\begin{array}{c}\text { Remifentanil } \\
\boldsymbol{n = 3 0}\end{array}$ & $\begin{array}{c}\text { Ketamine } \\
\boldsymbol{n}=\mathbf{3 0}\end{array}$ & $\boldsymbol{p}$ \\
\hline Positive & $6(20.0 \%)$ & $7(23.3 \%)$ & $0.754 \mathrm{C}$ \\
Negative & $24(80.0 \%)$ & $23(76.7 \%)$ & NS \\
\hline
\end{tabular}

$\boldsymbol{n}$ : number of cases; $\mathbf{C}$ : Chi-square test; NS: not significant at $p>0.05$ 
We found no significant difference in median grade 2 (G2) embryo count between Remifentanil and Ketamine groups ( $\mathrm{p}=$ 0.230). Moreover, there was no significant difference in median grade 3 (G3) embryo count between the groups $(\mathrm{p}=0.430)$. The comparison of rate of biochemical pregnancy outcome between groups is shown in Table 5 . Moreover, no significant difference in rate of biochemical pregnancy was found between groups $(\mathrm{p}=0.754), 6(20.0 \%)$ versus 7 (23.3 $\%)$, respectively.

\section{Discussion}

In the current study, between the Remifentanil and Ketamine groups, there was no significant difference in the mean age. However, a considerable fraction of both groups were over 35 years old. In women subjected to ART, age appears to be the single most important predictor of pregnancy (Joham, et al. ${ }^{[4]}$, Tan, et al. ${ }^{[8]}$ ). Indeed, low fertility in women as they get older is caused by a combination of causes including low ovarian reserve, poor oocyte quality, low number of retrieved oocytes, poor embryo quality, and less implantation rate, and less fertilization rate (Gleicher, et al. ${ }^{[9]}$, Khadra, et al. ${ }^{[10]}$ ). Results also showed no significant difference in mean body mass index (BMI) between both groups; nevertheless, most participants were either overweight or obese. In fact, obesity affects fertility in women harmfully by affecting endometrial receptivity and hormonal status (Silvestris, et al. ${ }^{[11]}$, Supramaniam, et al. $\left.{ }^{[12]}\right)$. In addition, the current study showed no significant difference in the mean duration of infertility between either group. It is worth mentioning that the lack of significant difference in mean duration of infertility between the Remifentanil and Ketamine groups with respect to age is mandatory in such case control studies to avoid bias in outcome variables, fertility parameters, biochemical pregnancy and general anesthesia characteristics to be attributed to significant variation in mean infertility duration between both study groups. It has been shown in a previous meta-analysis that solo duration of infertility is associated with a lower pregnancy rate (Matthiesen, et al. ${ }^{[13]}$ ). Herein, only two women admitted to being active smokers, one 
in the Remifentanil group and the other one in the Ketamine group. Therefore, the effect of smoking on outcomes in the current study will be relatively negligible because of the very small fraction of active smokers enrolled in the current study. It has been stated in previous reports that adverse ART outcomes are often seen in women with active smoking (Budani, et al. ${ }^{[14]}$, Rockhill, et al. ${ }^{[15]}$ ). Our results also indicated no significant difference in the frequency distribution of women according to type or cause of infertility between the groups. Therefore, the effect of type or cause of infertility did not affect outcome variables in both groups. Indeed, different success rates have been linked to different causes of infertility in couples undergoing ICSI. In addition, variation in ART outcome has been linked to variation in type of infertility, primary versus secondary (Ashrafi, et al. ${ }^{[16]}$ ). It was shown here that there was no significant difference in median serum ROS concentrations before and after anesthesia and in mean follicular fluid ROS concentrations between the Remifentanil and Ketamine groups. Therefore, either drug can be chosen for general anesthesia when performing oocyte retrieval without being afraid of significantly higher oxidative stress being associated with one drug than the other. After a thorough search of the available published articles, we were unable to find a study which is similar to parameters we measured to compare our results with it. However, previous experimental studies have demonstrated that Remifentanil is associated with ameliorating oxidative stress because it leads to lower levels of MDA. In another study, it was found that Ketamine administration was associated with a lower MDA level (Cho, et al. $\left.{ }^{[17]}\right)$. Therefore, with respect to oxidative stress, the use of drugs, Remifentanil and Ketamine, is safe. In the present study, there was no significant difference in the rate of biochemical pregnancy between the groups $(\mathrm{p}=0.754), 6$ (20.0\%) versus 7 (23.3\%), respectively. However, practically speaking, Ketamine resulted in a better biochemical pregnancy rate. Nevertheless, based on the results of the current study, choosing either Ketamine or Remifentanil will offer a comparable biochemical pregnancy outcome. Indeed, we 
disagree with the study by Mohsin et al in 2020 since we found no significant difference in pregnancy outcome between the Remifentanil and Ketamine groups; whereas, Mohsin et al in 2020, showed that Remifentanil was significantly associated with a higher pregnancy rate, $46.7 \%$ versus $20.0 \%$, respectively (Mohsin, et al. ${ }^{[6]}$ ). In one previous study, it has been shown that Remifentanil can offer a significantly better pregnancy rate (Yuzer, et al. ${ }^{[18]}$, Wilhelm, et al. $\left.{ }^{[19]}\right)$. In addition, some previous studies linked significantly lower pregnancy outcomes to Ketamine use (Jarahzadeh, et al. ${ }^{[20]}$ ). Therefore, to reach a consensus about the pregnancy rate in association with the use of Ketamine or Remifentanil, a larger study group is needed.

\section{Conclusions}

Remifentanil and Ketamine were associated with no significant variation in oocyte and embryo characteristics, and therefore, no one of them is superior to the other in this regard. Both Remifentanil and Ketamine were associated with comparable biochemical pregnancy outcomes, and therefore, there was no significant difference between them. Remifentanil and Ketamine were associated with no significant variation in ROS levels in serum and follicular fluid. Therefore, no one of them is superior to the other in this regard. Remifentanil was associated with a shorter recovery time, so it is superior to Ketamine in this regard. However, Remifentanil was associated with significantly lower systolic blood pressure than Ketamine.

\section{Acknowledgment}

We would like to acknowledge Al Nahrain University, Baghdad, Iraq.

\section{Funding}

This work received no funding.

\section{Author Contribution}

Abd Alhussain, A, performed the study, examined and reviewed results, and manuscript writing with the help and supervision of Reshan, RG, and Mossa, HAL.

\section{Conflict of Interest}

The authors declare no conflict of interest. 


\section{Ethical Clearance}

The study was approved by the Ethical Approval Committee.

\section{References}

[1] Griveau JF, Lannou DL. Reactive oxygen species and human spermatozoa: physiology and pathology. International Journal of Andrology. Wiley; 1997 Jul;20(2):61-9. [Online article link]

[2] Agarwal A, Gupta S, Sikka S. The role of free radicals and antioxidants in reproduction. Current Opinion in Obstetrics \& Gynecology. Ovid Technologies (Wolters Kluwer Health); 2006 Jun;18(3):325-32. [Online article link]

[3] Jauniaux E, Watson AL, Hempstock J, Bao Y-P, Skepper JN, Burton GJ. Onset of Maternal Arterial Blood Flow and Placental Oxidative Stress. The American Journal of Pathology. Elsevier BV; 2000 Dec;157(6):2111-22. [Online article link] [4] Joham AE, Teede HJ, Ranasinha S, Zoungas S, Boyle J. Prevalence of Infertility and Use of Fertility Treatment in Women with Polycystic Ovary Syndrome: Data from a
Large Community-Based Cohort Study. Journal of Women's Health. Mary Ann Liebert Inc; 2015 Apr;24(4):299-307. [Online article link]

[5] Urfalioglu A. Effect of Anesthetics During Oocyte Pick-Up Procedure on Oocyte Quality and Pregnancy. Journal of Clinical and Analytical Medicine; 2016 Nov 1;7(6): 840-843. [Online article link]

[6] Mohsin HAH, Reshan RG, Jawad MA. Comparison between Effects of Ketamine and Remifentanil Used During Oocyte Retrieval on ICSI Outcome. Systematic Reviews in Pharmacy. SynthesisHub Advance Scientific Research; 2020 Jun 1;11(04). [Online article link]

[7]Liu Y, Lin D, Wu B, Zhou W. Ketamine abuse potential and use disorder. Brain Research Bulletin. Elsevier BV; 2016 Sep;126:68-73. [Online article link]

[8] Tan T, Lau S, Loh S, Tan H. Female ageing and reproductive outcome in assisted reproduction cycles. Singapore Medical Journal. Singapore Medical Journal; 2014 Jun 30;55(6). [Online article link] 
[9] Gleicher N, Kushnir VA, Albertini DF, Barad DH. Improvements in IVF in women of advanced age. Journal of Endocrinology. Bioscientifica; 2016 Jul;230(1):F1-F6. [Online article link]

[10] Khadra MM, Freij MA, Al-Mazaydeh ZA, Al-Mashhrawi SE, Rahhal BO, Saleh SS, Kilani RM, Tahtamouni LH. Factors influencing successful pregnancy outcomes in IVF cycles among Jordanian infertile couple. Clinical and Experimental Obstetrics \& Gynecology; 2018; 45(6):855860. [Online article link]

[11] Silvestris E, de Pergola G, Rosania R, Loverro G. Obesity as disruptor of the female fertility. Reproductive Biology and Endocrinology. Springer Science and Business Media LLC; 2018 Mar 9;16(1). [Online article link]

[12] Supramaniam PR, Mittal M, McVeigh E, Lim LN. The correlation between raised body mass index and assisted reproductive treatment outcomes: a systematic review and meta-analysis of the evidence. Reproductive Health. Springer Science and
Business Media LLC; 2018 Feb 27;15(1). [Online article link]

[13] Matthiesen SMS, Frederiksen Y, Ingerslev HJ, Zachariae R. Stress, distress and outcome of assisted reproductive technology (ART): a meta-analysis. Human Reproduction. Oxford University Press (OUP); 2011 Aug 1;26(10):2763-76. [Online article link]

[14] Budani MC, Fensore S, Di Marzio M, Tiboni GM. Cigarette smoking impairs clinical outcomes of assisted reproductive technologies: A meta-analysis of the literature. Reproductive Toxicology. Elsevier BV; 2018 Sep;80:49-59. [Online article link]

[15] Rockhill K, Tong VT, Boulet SL, Zhang Y, Jamieson DJ, Kissin DM. Smoking and Clinical Outcomes of Assisted Reproductive Technologies. Journal of Women's Health. Mary Ann Liebert Inc; 2019 Mar;28(3):314-22. [Online article link]

[16] Ashrafi M, Sadatmahalleh SJ, Akhoond MR, Ghaffari F, Zolfaghari Z. ICSI outcome in infertile couples with different causes of 
infertility: a cross-sectional study. International journal of fertility \& sterility, 2013;7(2):88-95. [Online article link]

[17] Cho SS, Rudloff I, Berger PJ, Irwin MG, Nold MF, Cheng W, et al. Remifentanil ameliorates intestinal ischemia-reperfusion injury. BMC Gastroenterology. Springer Science and Business Media LLC; 2013 Apr 22;13(1). [Online article link]

[18] Yuzer H, Yuzbasioglu MF, Ciralik H, Kurutas EB, Ozkan OV, Bulbuloglu E, et al. Effects of Intravenous Anesthetics on Renal Ischemia/Reperfusion Injury. Renal Failure. Informa UK Limited; 2009 Jan;31(4):2906. [Online article link]

[19] Wilhelm W, Hammadeh ME, White PF, Georg T, Fleser R, Biedler A. General anesthesia versus monitored anesthesia care with remifentanil for assisted reproductive technologies: effect on pregnancy rate. Journal of Clinical Anesthesia. Elsevier BV; 2002 Feb;14(1):1-5. [Online article link]

[20] Jarahzadeh MH, Davar R, Hajiesmaeili MR, Entezari A, Musavi F. Remifentanil versus Fentanyl for Assisted Reproductive Technologies: Effect on Hemodynamic
Recovery from Anesthesia and Outcome of ART Cycles. International journal of fertility \& sterility. 2011;5(2):86-89. [Online article link]

\section{Peer Review Information}

Double-Blind Peer Review in which both authors and reviewers does not know each other.

This work was reviewed by

Asst. Prof. Dr. Laith Abbas Al-Huseini

Asst. Prof. Rana abdul Rasool Ridha Al.saadi

\section{Editorial Policy}

The editorial policy at IJEIR ensured that this article fit the standards of scientific publications.

This work was copyedited by

\section{Dr. Taif Alawsi}

\section{Authors at OrcID}

Hayder A. L. Mossa https://orcid.org/0000-0001-67332964 


\section{Authors Biographies}

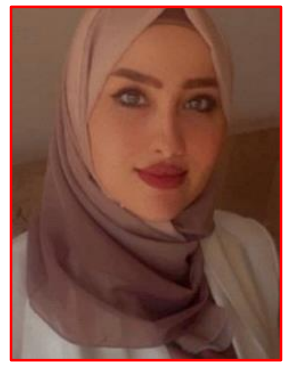

\section{Athraa Abd Alhussain}

She received her B.Sc. degree in Biology from Madinat Al-Elm University College in 2018. She works as a laboratory technician since graduation in private labs. She published a research article and was involved in many scientific activities. Recently, she graduated with an M.Sc. degree from the High Institute of Infertility Diagnosis and Assisted Reproductive Technologies, Al Nahrain University, Baghdad, Iraq.

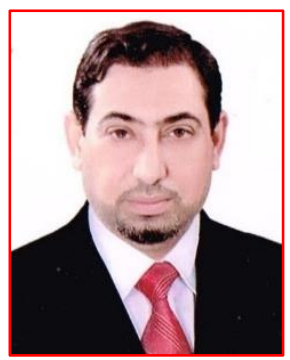

\section{Dr. Raad Ghazi Reshan}

Received his M.B.Ch.B. from the College of Medicine, Babylon University in 2003. He occupied the position of rotator house officer in AlHussein teaching hospital in Karbala city from 2003-2004. He worked in Al-Hilla surgical Hospital as an Anesthesia permanent from 2005 to 2006. In 2007 Started studying for the Board of Anesthesia at Al- Kadhymia teaching hospital. In 2010 he graduated as a senior Anesthesia specialist. He worked as a specialist in Al-Sader General Hospital in Missan city from 2011 - 2015. From 2016 till now he worked as a specialist of Anesthesia (Instructor) in the high Institute of infertility diagnosis and Assisted Reproductive Technologies, Al Nahrain University.

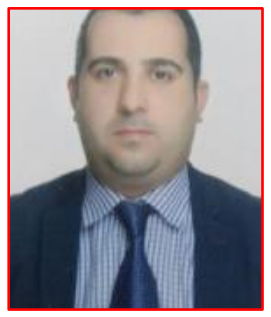

\section{Dr. Hayder A. L. Mossa}

$\mathrm{He}$ is an assistant professor at $\mathrm{Al}$ Nahrain University. He is a member of the Iraqi Society of Fertility, Iraqi
Society of Zoonotic Diseases (ISZD) \& Iraqi Zoonotic Communicable Diseases (ISZCD), Iraqi Academics Syndicate, European Society of Human Reproduction and Embryology (ESHRE). An editorial board member of Merit Research Journal of Medicine and Medical Sciences (MRJMMS), International Journal of Medical Research \& Health Sciences (IJMRHS). A reviewer at global journals Inc. (USA). He was a candidate for the award of Arabian Young Researchers in 2007. He granted for many appreciation certificates in the scientific \& administrative fields. He participated \& supervised in more than 60 scientific \& medical conferences, workshops \& training course. Has many kinds of research \& articles published in Iraqi \& national medical journals. Chief \& member of nearly 60 scientific \& administrative committees from 2006-till now. Has interests in assisted reproductive technologies, reproductive micromanipulation, medical terminology, research methods and seminars, reproductive physiology, advanced embryology.

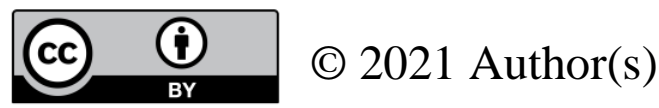

This article is licensed under a Creative Commons Attribution 4.0 International License, which permits use, sharing, adaptation, distribution and reproduction in any medium or format, as long as you give appropriate credit to the original author(s) and the source, provide a link to the Creative Commons license, and indicate if changes were made.

http://creativecommons.org/licenses/by/4.0/. 